
distance from breakpoint in human gross

Received

2 October 2014

Accepted

14 January 2015

Published

6 February 2015

Correspondence and requests for materials should be addressed to

N.A. (nevim.aygun@ gmail.com) \section{gene deletions}

\author{
Nevim Aygun
}

Department of Medical Biology, Faculty of Medicine, Dokuz Eylul University, Inciralti, Izmir, Turkey.

Long inverted repeats (LIRs) have been shown to induce genomic deletions in yeast. In this study, LIRs were investigated within $\pm 10 \mathrm{~kb}$ spanning each breakpoint from 109 human gross deletions, using Inverted Repeat Finder (IRF) software. LIR number was significantly higher at the breakpoint regions, than in control segments $(P<0.001)$. In addition, it was found that strong correlation between $5^{\prime}$ and $3^{\prime}$ LIR numbers, suggesting contribution to DNA sequence evolution $(r=0.85, P<0.001) .138$ LIR features at $\pm 3 \mathrm{~kb}$ breakpoints in $89(81 \%)$ of 109 gross deletions were evaluated. Significant correlations were found between distance from breakpoint and loop length $(r=-0.18, P<0.05)$ and stem length $(r=-0.18, P<$ 0.05 ), suggesting DNA strands are potentially broken in locations closer to bigger LIRs. In addition, bigger loops cause larger deletions $(r=0.19, P<0.05)$. Moreover, loop length $(r=0.29, P<0.02)$ and identity between stem copies $(r=0.30, P<0.05)$ of $3^{\prime}$ LIRs were more important in larger deletions. Consequently, DNA breaks may form via LIR-induced cruciform structure during replication. DNA ends may be later repaired by non-homologous end-joining (NHEJ), with following deletion.

ong inverted repeats (LIRs) are imperfect or near to perfect repetitive DNA sequence elements that can form secondary stem-loop structures in prokaryotic and eukaryotic genomes ${ }^{1-3}$. LIRs may induce stem loops through matching complementary repeats placed in inverted orientation, convertible to the hairpins in single stranded DNA or cruciforms in double stranded DNA ${ }^{4,5}$. It was found that LIRs involved deletion and recombination events in yeast Saccharomyces cerevisiae ${ }^{6,7}$.

Gross gene deletions are genomic rearrangements that can be observed in many types of human cancers and inherited diseases ${ }^{8-13}$. Deletion and duplication mutations can vary in size from thousands to hundreds of thousands of base pairs in length in the human genome ${ }^{14}$. It has been proposed that three major mechanisms are responsible for genomic rearrangements, including human genome deletions ${ }^{15}$. They are non-allelic homologous recombination (NAHR), non-homologous end-joining (NHEJ), and fork stalling and template switching (FoSTeS) models. Some genomic rearrangements are recurrent, with a common size and fixed breakpoints between low copy repeats (LCRs). Recurrent rearrangements are mostly mediated by NAHR between two $\mathrm{LCRs}^{16}$. Conversely, non-recurrent rearrangements have different sizes and distinct breakpoints in each event, and are performed by NHEJ and FoSTeS models ${ }^{15}$. Gu et al. suggests that the FoSTeS model is a replication-based rearrangement pathway that may operate over long distances (from 120 to $550 \mathrm{~kb}$ ) through template switching ${ }^{15}$. Alternatively, it has been proposed that palindrome or cruciform structures may stimulate the FoSTeS model ${ }^{15}$.

Breakpoints of gross gene deletions coincide with non-B DNA conformations, including hairpin/cruciform structures $^{17}$. Hairpins are reported to form by direct repeats ${ }^{18}$. Direct repeats have ranges from 2 to $8 \mathrm{bp}$, and are associated with small deletion breakpoints in human genetic diseases ${ }^{19}$. Moreover, retinoblastoma gene deletion involves direct repeats within the deletion breakpoints ${ }^{20}$.

Short direct repeats were also detected in 15 proximal breakpoints of the dystrophine gene, which has large deletions ${ }^{21}$. Short IRs and IR inversions were found in $83 \%$ of deletions + small insertions, while short direct repeats were detected only in simple deletion breakpoints ${ }^{22}$.

Two highly homologous $\mathrm{Alu}$ repeats in inverted orientations were found in the vicinity of gross deletion breakpoints in the von Willebrand factor $(V W F)$ gene ${ }^{23}$. Furthermore, LINEs, LTR repetitive elements, and SINEs (including Alus), were enriched at breakpoints of rare pathogenic microdeletions ${ }^{24}$. Vissers et al. also 
suggests that microhomology levels of breakpoint junctions play an important role in replication-based mechanisms, such as FoSTeS and microhomology-mediated break-induced replication $(\mathrm{MMBIR})^{24}$. Zhang et al. also suggested replication fork stalling to initiate FoSTeS ${ }^{25}$.

Gordenin et al. showed that LIRs cause deletion in Saccharomyces cerevisiae ${ }^{6}$. Lobachev et al. suggested they form stem-like secondary structures on single stranded DNA during replication, thereby causing deletions ${ }^{26}$. Warburton et al. found that some IRs are capable of transforming into cruciform structures, with intrastrand double helices, termed stems and unpaired loops forming internal spacers ${ }^{1}$. The four-way junction of this suggested IR pattern is similar to the Holliday structure. Eichman et al. showed formation of the Holliday junction in synthetic IR DNA using X-ray crystallography ${ }^{27}$. From this work, it was proposed that IRs may be involved in homologous recombination. Bacolla and Wells indicated that IRs may form cruciform structures, and are often found at genomic rearrangement breakpoints $^{18}$.

Genomes of many complex organisms have been investigated for larger IRs. It was determined that higher eukaryotic genomes include many imperfect and near-to-perfect LIRs ${ }^{28-31}$. In mice, a perfect LIR was shown to create a large deletion ${ }^{32}$. Subsequently, it was decided that criteria for LIRs in genomic rearrangements involved recombination. In this regards, Wang and Leung reported that LIRs with stem length $>30 \mathrm{bp}$, identity between stem copies (hereafter stem identity) $>85 \%$ and internal spacer of $<2 \mathrm{~kb}$, are recombinogenic in genomes of humans and some other organisms ${ }^{2}$. Voineagu et al. demonstrated that Alu IRs with $100 \%$ sequence homology of stem copies, triggers strong replication blockage ${ }^{3}$. However, Alu IRs with $75 \%$ stem identity between repetitive halves caused mild replication blockage in $E$. coli cells ${ }^{3}$.

Potential models referred to as replication slippage and hairpin nicking were proposed by Akgün et al. to explain the mechanism underlying LIR induced deletions ${ }^{4}$. With these models, many deletions formed inside palindrome stems or loops are explained. However, alternative models are required for clarifying the mechanisms of larger deletions formed in close proximity to palindromes. To understand how gross gene deletions occur in human cancers and inherited diseases, this present study investigated the significance of LIRs on breakpoint regions of human gross gene deletions.

\section{Results}

Identification of long inverted repeats in breakpoint regions of gross gene deletions. Sequences from 218 breakpoint regions of 63 gross gene deletions were taken from references 33-89 (see Supplementary Table S1 online) listed in the $\mathrm{HGMD}^{90,91}$ and GRaBD $^{92,93}$ (Figure 1a). LIRs with stem length $>20 \mathrm{bp}$ on surrounding $( \pm 10 \mathrm{~kb})$ each breakpoint were investigated using $\mathrm{IRF}^{94,95}$ (Figure $1 \mathrm{~b}$ ). In total, 218 genomic regions, including $5^{\prime}$ and $3^{\prime}$ breakpoints from 109 gross deletions involving 63 different genes (Table 1), were analysed. Total number of LIRs was determined within $\pm 10 \mathrm{~kb}$ regions flanking each breakpoint. In the deletion group, a total of 2723 LIRs were detected (see Supplementary Table S2 online). A total of 1345 LIRs were also identified in $20 \mathrm{~kb}$ segments from 220 control sequences (see Supplementary Table S2 online).

Mean ranks of LIR numbers were compared between gross deletion breakpoints and control sequences using the Mann Whitney $U$ test.The mean LIR number was significantly higher at the breakpoint regions from gross gene deletions, than in control group $(P<0.001)$.

In addition, associations between $5^{\prime}$ and $3^{\prime}$ LIR numbers within $\pm 10 \mathrm{~kb}$ regions flanking each breakpoint were determined using Pearson's correlation coefficients. Positive, strongly significant association was found between LIR numbers from $5^{\prime}$ and $3^{\prime}$ breakpoints in 109 gross deletions $(r=0.85, P<0.001)$.
Additionally, Spearman's correlation showed that a negative moderately significant associations were found between deletion size and $5^{\prime}$ LIR number $\left(r_{s}=-0.30, P<0.003\right)$, and $3^{\prime}$ LIR number $\left(r_{s}=\right.$ $-0.30, P<0.002)$ in 109 gross deletions respectively.

Features of LIRs selected within $\pm 3 \mathrm{~kb}$ genomic regions flanking $5^{\prime}$ and $3^{\prime}$ deletion breakpoints. Next, LIRs were selected using appropriate criteria (outlined in Materials and Methods) (Figure 1c). Properties of these selected LIRs from $5^{\prime}$ and $3^{\prime}$ breakpoints were analysed. In total, $138 \mathrm{LIRs}$ at distance of $0-3 \mathrm{~kb}$ from breakpoints, with stem length $>20 \mathrm{bp}$, internal spacer of $0-2.5 \mathrm{~kb}$, and stem identity $>70 \%$ were detected (see Supplementary Table S3 online). The stem lengths and identities, internal spacer (loop) lengths and distances from breakpoints of LIRs were determined at the breakpoint locations of genes involved in gross deletions, including PINK1 (NG_008164.1; 5001-23057), ATM (U82828.1; 10722156953), PTEN (NT_030059.12; 613176-718513) and BRCA1 (L78833.1; 3344-84436) (Figure 2).

Distribution of LIRs at the $5^{\prime}$ and $3^{\prime}$ breakpoint regions from gross gene deletions. LIR distribution was also examined at the 218 genomic locations, including $5^{\prime}$ and $3^{\prime}$ breakpoint regions from 109 gross gene deletions (see Supplementary Figure S1 online). From these 218 locations, 138 LIRs were detected at the 5' and/or 3' breakpoints from 89 gross gene deletions (Figure 3a). Moreover, 49 of 89 gross deletions had 98 LIRs in both 5' and 3' deletion breakpoints (Fig. 3b), and 40 of 89 gross deletion had LIR at the $5^{\prime}$ or $3^{\prime}$ breakpoint sites (Figure $3 \mathrm{c}$ ).

Correlations between LIR features such as length and identity of stem, internal spacer length and distance from breakpoint, and also deletion size in $\mathbf{8 9}$ gross gene deletions. In all identified 138 LIRs, at the $5^{\prime}$ and/or $3^{\prime}$ breakpoints in 89 (81\%) of 109 gross deletions had stem lengths between 24 and $973 \mathrm{bp}$ (see Supplementary Fig. S2 online), with stem identities between 70.54 and $100 \%$ (see Supplementary Figure S3 online). These LIRs were located at the distance of $\pm 0-2,539$ bp from $5^{\prime}$ and $3^{\prime}$ breakpoints (see Supplementary Fig. S4 online), with internal spacer lengths between 0 and 2,435 bp (see Supplementary Figure S5 online).

Associations between features of these LIRs were examined using Pearson's correlation coefficient. Low to moderately significant correlations were found between certain LIR features (e.g. stem length and identity, internal spacer length and distance from breakpoint). In all 138 LIRs located at the regions including $5^{\prime}$ and $3^{\prime}$ breakpoints, negative correlations were found between stem length and stem identity $(r=-0.49, P<0.001)$, internal spacer length and distance from breakpoint $(r=-0.18, P<0.05)$, stem length and distance from breakpoint $(r=-0.18, P<0.05)$, and internal spacer length and stem identity $(r=-0.17, P<0.05)$. Conversely, a moderately positive correlation was found between internal spacer length and stem length $(r=0.27, P<0.002)$. No correlation was found between stem identity and distance from breakpoint $(r=-0.008, P>0.1)$.

Moreover, associations between gross gene deletion size and features of the 138 LIRs were analysed by Pearson's correlation coefficient. It was found that positive significant correlation between internal spacer length and deletion size $(r=0.19, P<0.05)$. However, no correlations were found between deletion size and three other LIR features, specifically, stem length $(r=0.01, P>0.1)$, stem identity $(r=-0.06, P>0.1)$, and distance from breakpoint $(r=$ $0.08, P>0.1)$.

In addition, $5^{\prime}$ and $3^{\prime}$ LIR features from 89 gross deletions were reexamined individually. Thus, associations between properties of 70 and 68 LIRs located on $5^{\prime}$ and $3^{\prime}$ breakpoints, respectively, and deletion size, were analysed by Pearson's coefficient. Negative moderate to strong correlations were found between internal spacer length and stem identity $(r=-0.28, P<0.02)$, and stem length 


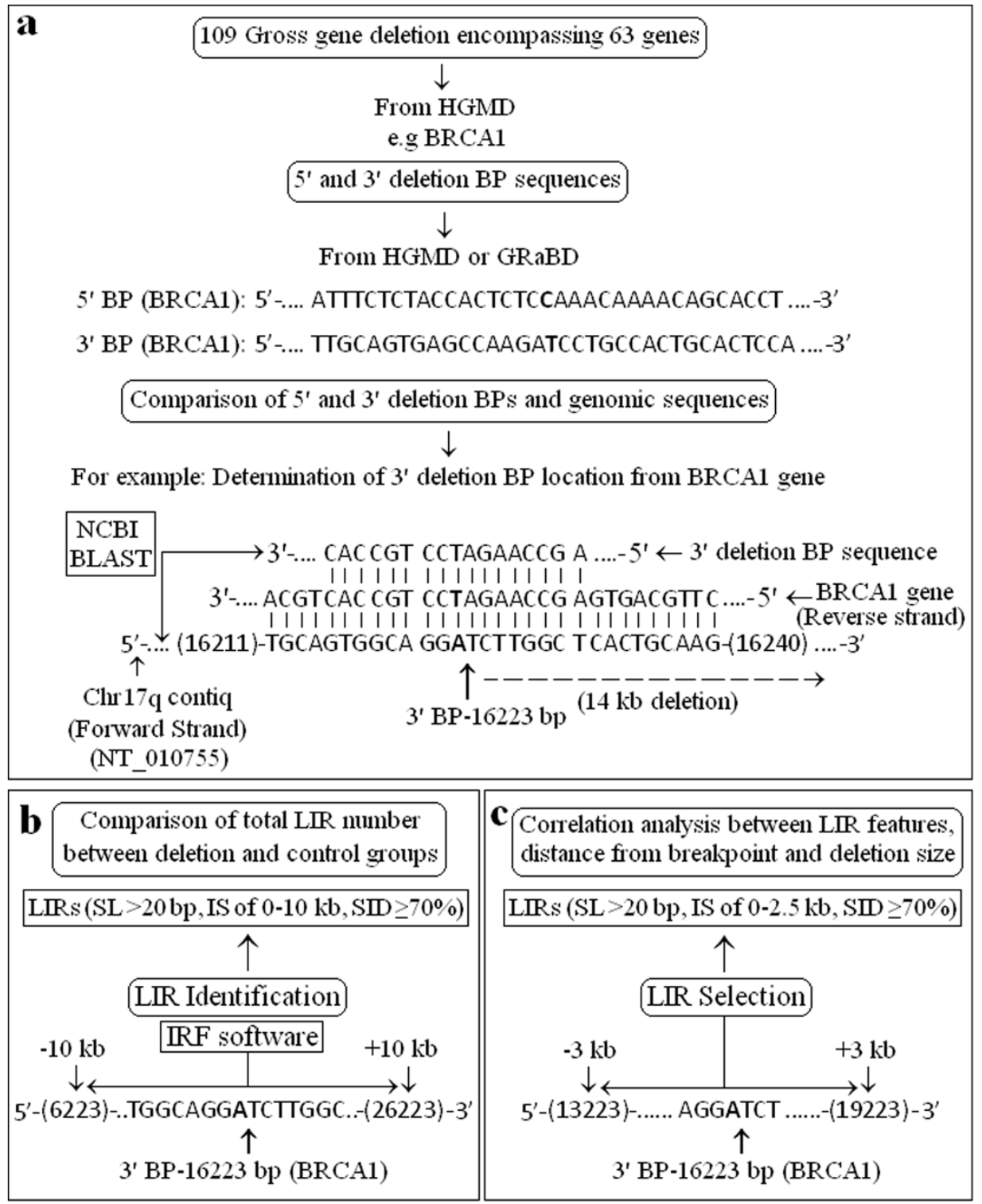

Figure $1 \mid$ LIR identification and selection were performed in 218 genomic regions including $5^{\prime}$ and $3^{\prime}$ breakpoints from 109 gross deletions involving 63 human genes using IRF software. (a) DNA sequences from $5^{\prime}$ and $3^{\prime}$ deletion BPs were obtained from HGMD and GRaBD. Each BP-DNA sequence and corresponding gene was compaired using NCBI BLAST. Deletion BP locations were determined in related genes. $3^{\prime}$ BP sequence from BRCA1 gene was presented for describing BLAST comparing process. (b) LIR identification was done within $\pm 10 \mathrm{~kb}$ flanking sequences each of $5^{\prime}$ and $3^{\prime}$ deletion BPs and $20 \mathrm{~kb}$ DNA fragments from control groups using IRF. LIRs with SL $>20 \mathrm{bp}$, IS of $0-10 \mathrm{~kb}$, SID $\geq 70 \%$ were included for comparing total LIR number between deletion and control groups using Mann Whitney $U$ test. (c) LIR selection was made within $\pm 3 \mathrm{~kb}$ flanking sequences each of $5^{\prime}$ and $3^{\prime}$ BPs in deletion group. LIRs with SL $>20 \mathrm{bp}$, IS of $0-2.5 \mathrm{~kb}, \mathrm{SID} \geq 70 \%$ were selected for analysing of correlations between LIR features, distance from breakpoint and deletion size using Pearson's coefficient. Abbreviations: Bp, base pair; BP, breakpoint; GRaBD, gross rearrangement breakpoint database; HGMD, human gene mutation database; IRF, inverted repeat finder; IS, internal spacer; kb, kilobase; LIR, long inverted repeat; SID, stem identity; SL, stem length.

and stem identity $(r=-0.57, P<0.001)$ for LIRs within $5^{\prime}$ breakpoints.

A positive moderate correlation was found between internal spacer length and stem length $(r=0.35, P<0.004)$ for LIRs within $3^{\prime}$ breakpoints. In addition, negative moderate correlations were found between stem identity and stem length $(r=-0.40, P<$ $0.002)$, and distance from breakpoint and stem length $(r=-0.31$, $P<0.02$ )

Furthermore, positive moderately significant correlation was found between internal spacer length of $3^{\prime}$ LIRs and deletion size $(r=0.29, P<0.02)$. However, no correlation was found between internal spacer length of $5^{\prime}$ LIRs and deletion size $(r=-0.16, P>$
$0.1)$. No correlations were found between deletion size and three other LIR features, specifically, stem length $\left(5^{\prime}: r=-0.06, P>\right.$ $\left.0.1 ; 3^{\prime}: r=0.04, P>0.1\right)$, stem identity $\left(5^{\prime}: r=0.12, P>0.1 ; 3^{\prime}\right.$ : $r=-0.10, P>0.1)$, and distance from breakpoint $\left(5^{\prime}: r=0.22, P>\right.$ $\left.0.05 ; 3^{\prime}: r=0.08, P>0.1\right)$.

Correlations between stem length and identity, internal spacer length and distance from breakpoint, and also deletion size in 49 gross gene deletions including LIRs at both of $5^{\prime}$ and $3^{\prime}$ breakpoints. In addition, 98 LIRs were identified in both $5^{\prime}$ and $3^{\prime}$ breakpoints from 49 of 89 gross gene deletions (Figure 3b). These LIRs had stem identities of 71.65-100\%, stem lengths of 27-603 bp, 
and internal spacer lengths of 0-2,435 bp (see Supplementary Table S3 and Figure S6 online). Features of these 98 LIRs were analysed using Pearson's correlation coefficient. Low to moderately significant correlations were found between certain LIR features, including stem length, stem identity, loop length and distance from breakpoint. Positive correlation was found between internal spacer length and stem length $(r=0.23, P<0.05)$. Negative moderate correlations were found between stem identity and stem length $(r=-0.39, P<0.001)$, and distance from breakpoint and stem length $(r=-0.31, P<0.003)$. However, no correlations were found between internal spacer length and stem identity $(r=-0.08$, $P>0.1)$, internal spacer length and distance from breakpoint $(r=$ $-0.13, P>0.1)$, and stem identity and distance from breakpoint $(r=$ $0.06, P>0.1)$.

Furthermore, $5^{\prime}$ and $3^{\prime}$ breakpoint regions of these 98 LIRs were examined individually. Associations between LIR features from $5^{\prime}$ and $3^{\prime}$ breakpoint locations and gross gene deletion size in 49 gross deletions were analysed by Pearson's correlation method. A negative moderate correlation was found between stem length and distance from breakpoint for LIRs in $5^{\prime}$ breakpoint regions $(r=-0.30, P<$ $0.05)$. Negative moderate correlation was also found between stem length and distance from breakpoint for LIRs in $3^{\prime}$ breakpoint regions $(r=-0.33, P<0.05)$. Strong negative correlation was found between stem length and stem identity from $3^{\prime}$ LIRs $(r=-0.51, P<$ $0.001)$. Positive moderate correlation was found between stem length and internal spacer length from $3^{\prime}$ LIRs $(r=0.36, P<0.02)$.

In addition, the relationship between $5^{\prime}$ and $3^{\prime}$ LIRs were analysed. Positive moderate correlation was found between distance from breakpoint for $5^{\prime}$ LIRs and stem identity of $3^{\prime}$ LIRs, involving 49 gross gene deletion regions $(r=0.28, P<0.05)$.

Associations between deletion size and $5^{\prime}$ and $3^{\prime}$ LIR features from these 49 gross deletions were also analysed by Pearson's correlation method. Negative moderate correlation was found between stem identity of $5^{\prime}$ LIRs and deletion size $(r=-0.40, P<0.005)$. Positive moderate correlation was found between stem identity of $3^{\prime}$ LIRs and deletion size $(r=0.30, P<0.05)$. However, no correlations were found between deletion size and loop length $\left(5^{\prime}: r=\right.$ $\left.-0.04, P>0.1 ; 3^{\prime}: r=0.04, P>0.1\right)$, stem length $\left(5^{\prime}: r=0.17, P\right.$ $\left.>0.1 ; 3^{\prime}: r=-0.18, P>0.1\right)$, and distance from breakpoint $\left(5^{\prime}: r=\right.$ $\left.0.11, P>0.1 ; 3^{\prime}: r=-0.10, P>0.1\right)$.

Correlations between length and identity of stem, internal spacer length and deletion size in $\mathbf{4 0}$ gross gene deletions including LIRs spanning $5^{\prime}$ or $3^{\prime}$ breakpoints. LIRs were also identified at the other 40 gross gene deletions containing LIRs in $5^{\prime}$ or $3^{\prime}$ breakpoints. In total, 21 and 19 of the 40 LIRs from $5^{\prime}$ and $3^{\prime}$ breakpoint sites, respectively, were analysed (Figure 3c). LIRs had stem identities of $70.54-100 \%$, stem lengths of 24-973 bp, and internal spacer lengths of $0-2,422 \mathrm{bp}$, and were located at the distance of $0-2,311 \mathrm{bp}$ from breakpoints (see Supplementary Table S3 online).

Associations between LIR features were analysed by Pearson's correlation coefficient. Moderate to strong significant correlations were found between LIR features, including stem length and stem identity, and internal spacer length and distance from breakpoint. In 40 LIRs, a positive moderate correlation was found between internal spacer length and stem length $(r=0.34, P<0.05)$. In addition, negative correlations were found between internal spacer length and stem identity $(r=-0.33, P<0.05)$, and stem length and stem identity $(r=-0.61, P<0.001)$. However, no correlations were found between distance from breakpoint and internal spacer length $(r=-0.25, P>0.1)$, stem length $(r=-0.02, P>0.1)$, or stem identity $(r=-0.12, P>0.1)$.

Deletion size and LIR features were also analysed by Pearson's correlation method. A positive moderate correlation was found between internal spacer length of LIRs and deletion size $(r=0.35$, $P<0.05)$. However, no correlations were found between deletion 


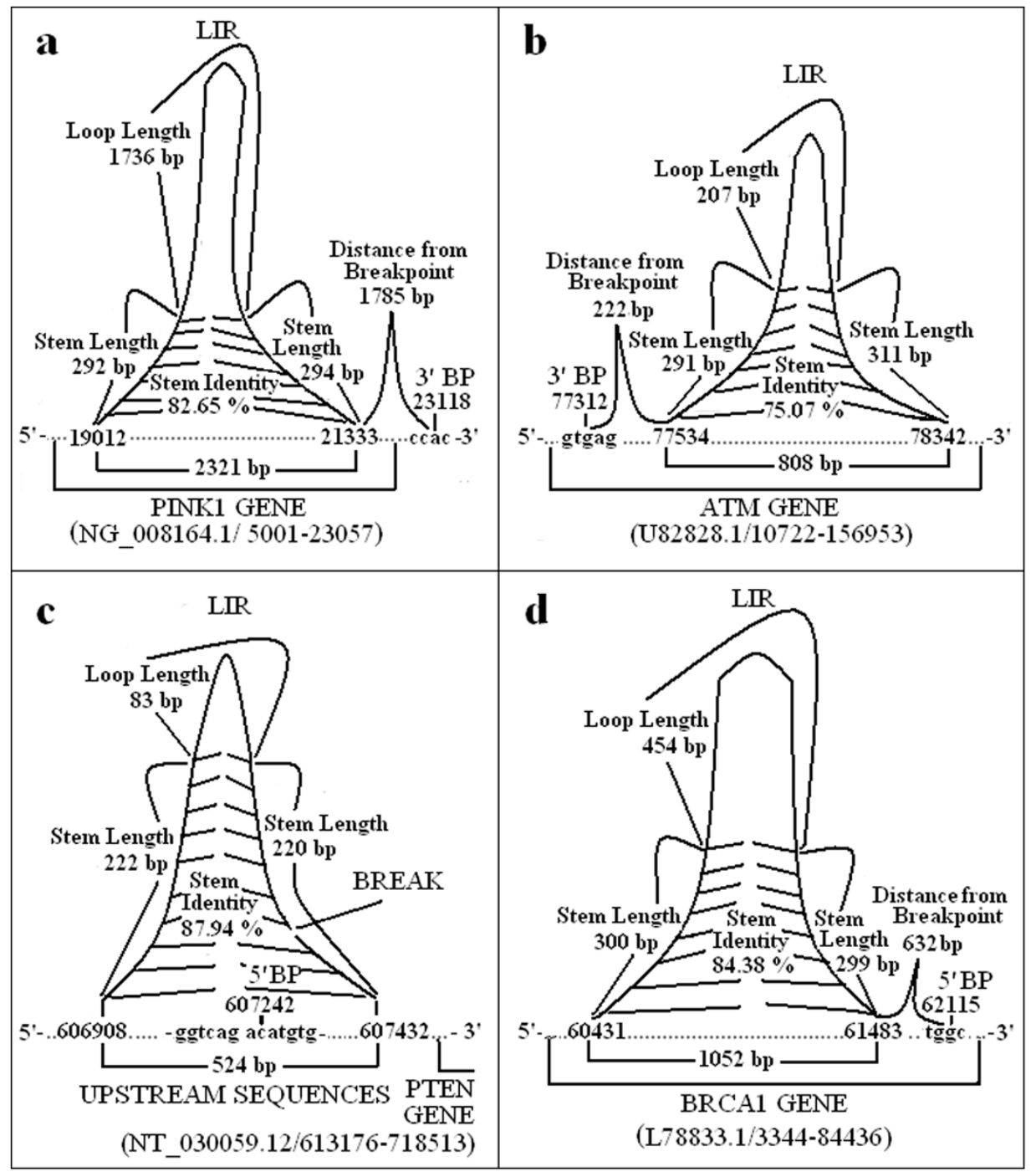

Figure $2 \mid$ Breakpoint regions of PINK1, ATM, PTEN and BRCA1 genes. Sizes of LIR features, e.g. stem length, stem identity and internal spacer (loop length) are shown. NCBI accession numbers of each gene are provided. Coordinates correspond to GenBank sequences. (a) 3' breakpoint sequence of the PINK1 deletion is in the downstream of gene. The LIR of PINK1 is located at the upstream of 1785 bp from $3^{\prime}$ breakpoint, has a stem length of 292 bp, internal spacer of $1736 \mathrm{bp}$, and stem identity of $82.65 \%$. (b) $3^{\prime}$ breakpoint sequence of the ATM deletion is within the gene. The LIR of ATM is located at the $222 \mathrm{bp}$ downstream of $3^{\prime}$ breakpoint, and has a stem length of $291 \mathrm{bp}$, internal spacer of $207 \mathrm{bp}$, and stem identity of $75.07 \%$. (c) 5' breakpoint sequence of the PTEN deletion is in the upstream of gene. The LIR of PTEN includes $5^{\prime}$ breakpoint, and has a stem length of $220 \mathrm{bp}$, internal spacer of $83 \mathrm{bp}$, and stem identity of $87.94 \%$. (d) $5^{\prime}$ breakpoint sequence of the BRCA1 deletion is within the gene. The LIR of BRCA1 is located at the upstream of $632 \mathrm{bp}$ from $5^{\prime}$ breakpoint, and has a stem length of $299 \mathrm{bp}$, internal spacer of $454 \mathrm{bp}$, and stem identity of $84.38 \%$. Abbreviation: Bp, base pair; BP, breakpoint; LIR, long inverted repeat.

size and three other LIR features, specifically, stem length $(r=0.00$, $P>0.1)$, stem identity $(r=-0.08, P>0.1)$, and distance from breakpoint $(r=0.09, P>0.1)$.

Re-examination of LIRs detected in only one of regions spanning $5^{\prime}$ and $3^{\prime}$ breakpoints of gross gene deletions. The 40 gross gene deletions containing LIRs in only one of genomic regions spanning $5^{\prime}$ and 3' breakpoints were re-examined in terms of their ability to form new LIRs between breakpoints with LIRs and non LIRs in related deletion regions. LIRs with distance of $0-10 \mathrm{~kb}$ from breakpoints, stem identity $>70 \%$ and stem length $>150$ bp were analysed.

In 24 of the 40 gross deletions, new LIRs between 5 - and $10-\mathrm{kb}$ genomic segments from $5^{\prime}$ and $3^{\prime}$ breakpoints containing LIR or no LIR, respectively, were found (see Supplementary Table S4 online; Figure 4). From these 24 gross deletions, LIR stem identities and lengths were determined to be $70.19-86.66 \%$ and $173-1789 \mathrm{bp}$, respectively (Figure 5). In addition, these LIRs were located at distance of $\pm 42-9,330$ bp from breakpoints (Figure 5).

Features of these 24 LIRs were analysed by Spearman's correlation method. A strong significantly negative correlation was found between stem length and stem identity $\left(r_{s}=-0.51, P<0.02\right)$. No correlations were found between distance from breakpoint and stem length $\left(r_{s}=-0.08, P>0.1\right)$ or stem identity $\left(r_{s}=-0.08, P>0.1\right)$.

\section{Discussion}

Deletion breakpoints are often associated with Alu and non-B DNAforming elements such as short direct and inverted repeats, and inversions of inverted repeats in human genomic rearrangements ${ }^{17,19-23}$. In this study, LIRs within $\pm 10 \mathrm{~kb}$ regions flanking 218 breakpoint sequences from gross gene deletions in human cancers and inherited diseases, were investigated by using IRF ${ }^{94,95}$ software. As a program that uses an algorithm presented by Benson ${ }^{95}$, 
109 gross gene deletions

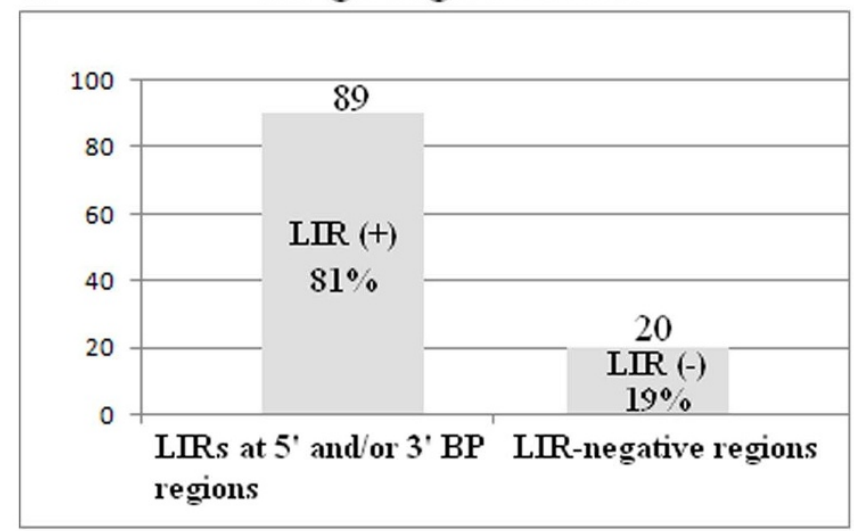

b 89 deletions with LIRs at $5^{\prime}$ and/or $3^{\prime}$ BP regions

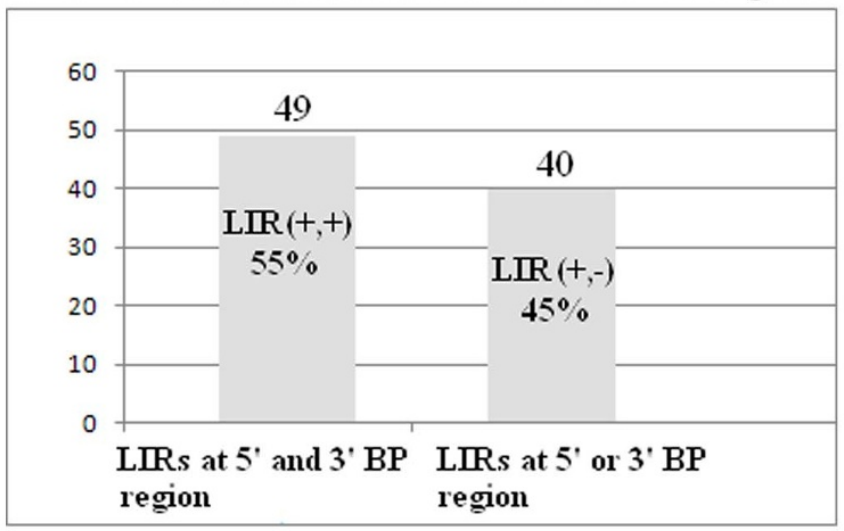

C 40 deletions with LIRs at $5^{\prime}$ or $3^{\prime} \mathrm{BP}$ regions

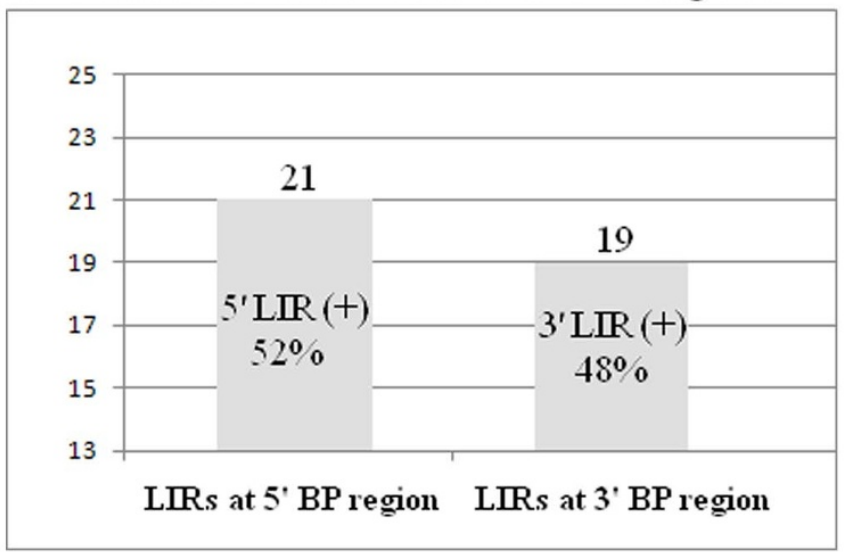

Figure $3 \mid$ Distribution of 138 LIRs at the $5^{\prime}$ and 3' BP regions of 109 gross gene deletions. (a) LIRs were detected in $89(81 \%)$ gene deletions. (b) In 49 of these deletions, LIRs were located at both 5' and 3' BP regions. (c) Among the 40 deletions with LIRs at one of the breakpoint regions, in 21, the LIRs were at the $5^{\prime}$ BP region, and in 19 deletions, at the $3^{\prime} \mathrm{BP}$ region. Abbreviations: BP, breakpoint; LIR, long inverted repeat.

IRF software can efficiently detect two or more contiguous approximate inverted repeats in sizes up to $700 \mathrm{~kb}$ at the same location on DNA sequences without the need to specify either the pattern or pattern size. In this way, IRF software served that present study accurately analyzes significance of relationship between LIR numbers and breakpoint regions in human gross gene deletions.

This work showed that the mean LIR number was significantly higher at the breakpoint regions of gross gene deletions, than in
Detecting of new LIRs between breakpoint regions in 40 gross deletions including LIR at the $5^{\prime}$ or $3^{\prime} \mathrm{BP}$

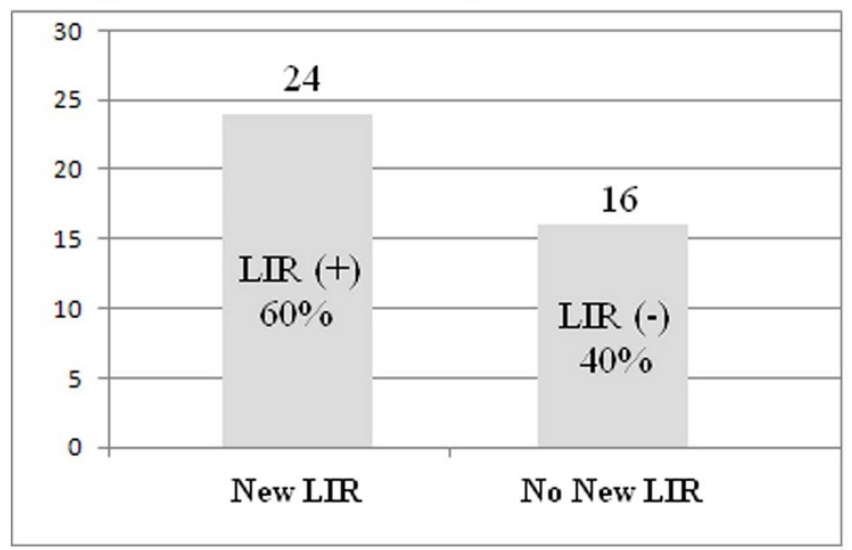

Figure 4 | Identification of new LIRs between breakpoint regions of gross gene deletions including LIR at only one of the $5^{\prime}$ and $3^{\prime}$ BPs. New LIRs were detected between genomic sequences flanking breakpoints in 24 of the 40 gross deletions including LIR at the $5^{\prime}$ or $3^{\prime}$ BP. Abbreviations: BP, breakpoint; LIR, long inverted repeat.

control group $(P<0.001)$. In addition, strongly significant positive correlation was found between $5^{\prime}$ and $3^{\prime}$ LIR numbers from breakpoint regions $(r=0.85, P<0.001)$. In this regards, increasing LIR numbers can cause or induce chromosomal rearrangements (including duplication, recombination and/or deletion) in human genome during evolutionary process.

Furthermore, negative moderately significant associations were found between deletion size and $5^{\prime}$ and $3^{\prime}$ LIR numbers $\left(r_{s}=\right.$ $\left.-0.30, P<0.003 ; r_{s}=-0.30, P<0.002\right)$ in 109 gross deletions, respectively. This result indicates that increasing $5^{\prime}$ or $3^{\prime}$ LIR numbers at the breakpoints cause smaller deletion sizes. Over-LIR intensity may impede efficiency, strengthens and further kinetic properties of inverted repeats because of competing LIRs with each other. Consequently, these findings suggest that DNA sequence evolution may also be prosecuted by LIRs in human genome.

In Saccharomyces cerevisiae, Saini et al. reported that IRs induce mutagenesis by break formation at distant sites (up to $8 \mathrm{~kb})^{96}$. Similarly, Lobachev et al. suggested that LIRs may stimulate recombination and deletion by forming secondary structures on the single strand DNA during replication ${ }^{26}$. In addition, Bacolla and Wells indicated that repetitive DNA motifs may fold into non-B DNA structures including cruciforms/hairpins, leading to genomic rearrangements associated with neurodegenerative and genomic disorders ${ }^{18}$.

In 138 LIRs identified in 89 gross deletion, significant associations were found between internal spacer length and distance from breakpoint $(r=-0.18, P<0.05)$, stem length and distance from breakpoint $(r=-0.18, P<0.05)$. These associations suggest DNA strand breaks potentially in locations close to larger LIRs. Similarly, Lobachev et al. reported that stimulation of deletions was positively correlated with IR $\operatorname{size}^{26}$. In addition, Lim et al. reported that IRs $\geq$ $800 \mathrm{bp}$ are required for gene deletion effectiveness in Saccharomyces cerevisiae, showing IRs improve gene deletion efficiency up to $1.2 \mathrm{~kb}^{97}$.

In addition, a positive significant correlation between internal spacer length and deletion size in 138 LIRs was found $(r=0.19$, $P<0.05$ ), suggesting LIRs with bigger loops cause larger deletions at fragile DNA sites. Weiss and Wilson reported that loops with 25247 nucleotides (nt) were efficiently and accurately repaired during homologous recombination ${ }^{98}$. It was suggested that bigger loops $(>247 \mathrm{nt})$ cannot repair and excise in homologous recombination 


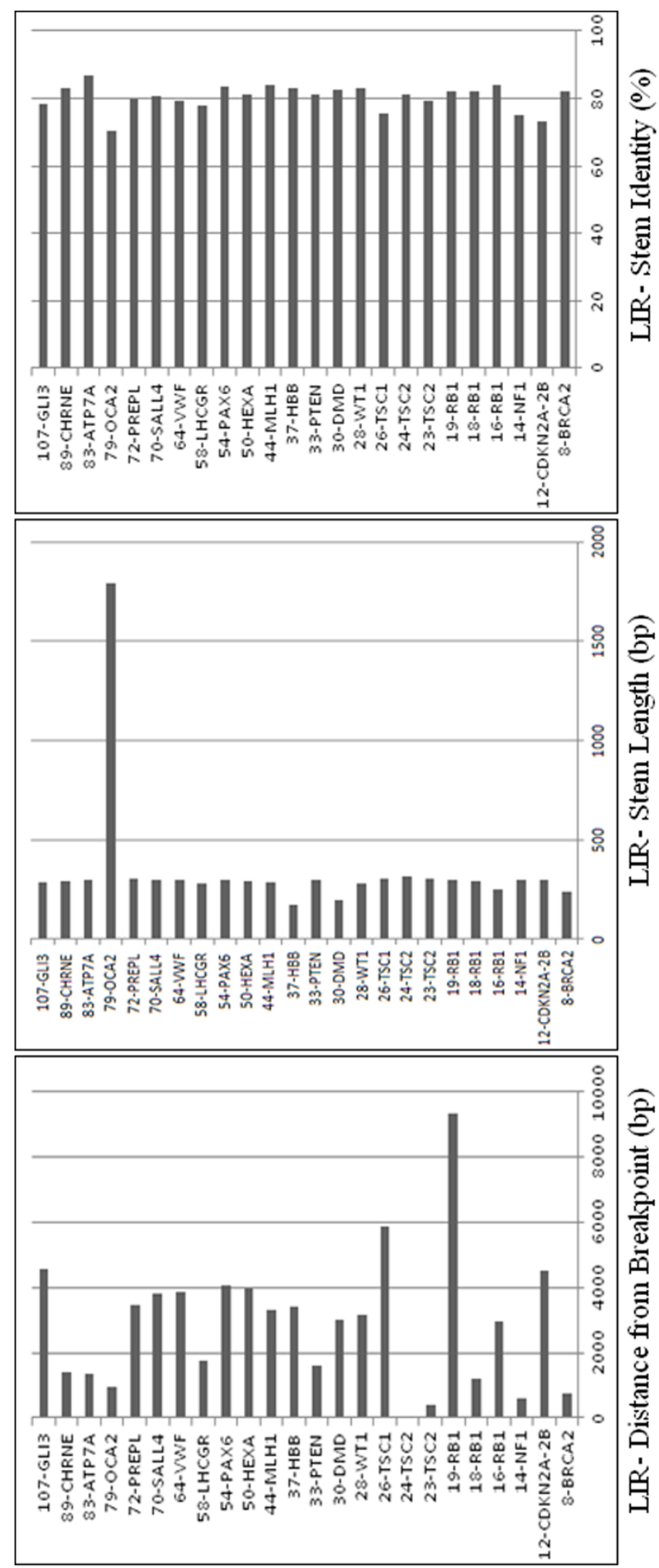

Figure $5 \mid$ In 24 gross deletion, new identified LIRs with stem identity, stem length and distance from breakpoint were shown. Black bars indicate stem length, stem identity and distance from breakpoint of LIRs found between distant sites. Abbreviations: Bp, base pair; LIR, long inverted repeat.

accurately, therefore cells with these loops may be subject to either apoptosis or NHEJ. If cells cannot induce apoptosis, it was suggested that LIRs > $247 \mathrm{nt}$ may break DNA, and be repaired by NHEJ.
In conclusion, larger deletions may more efficiently form by LIRs with larger loops at $5^{\prime}$ or $3^{\prime}$ breakpoints in human cancers and inherited diseases. DNA end may gain further kinetic properties, and match with distant brekpoint site (Figure 6).

Moreover, correlation between distance from breakpoint and stem length $(r=-0.31, P<0.02)$ was observed in $3^{\prime}$ LIRs from 89 gross deletions. These data suggest that DNA strand is potentially broken in locations closer to $3^{\prime}$ LIRs with larger stem lengths. In addition, a positive moderately significant correlation was found between deletion size and internal spacer length of $3^{\prime}$ LIRs $(r=0.29, P<0.02)$, with no correlation between internal spacer length of $5^{\prime}$ LIRs $(r=$ $-0.16, P>0.1)$. These results show that $3^{\prime}$ LIRs with bigger loops are more important than $5^{\prime}$ LIRs, for larger gross deletions in human genome.

Similarly, associations between deletion size and stem identities of $5^{\prime}(r=-0.40, P<0.005)$ and $3^{\prime}(r=0.30, P<0.05)$ LIRs were found in 49 gross deletions including LIR on the both of $5^{\prime}$ and $3^{\prime}$ breakpoints. These data suggest that $3^{\prime}$ LIRs with greater stem identities cause larger deletion sizes, while similar 5' LIRs cause smaller deletion sizes. Furthermore, a association between distance from breakpoint of $5^{\prime}$ LIRs and stem identity of $3^{\prime}$ LIRs $(r=0.28, P<0.05)$ was also found, suggesting $3^{\prime}$ LIRs with greater stem identities are more likely to induce DNA breakage than 5' LIRs.

Consequently, LIRs may induce DNA breakages at the nearby locations through forming cruciform structures. Free DNA ends between distant sites may come together by NHEJ, with following gene deletion (Figure 7). Similarly, Varga and Aplan reported that DNA breaks produced various deletions exhibiting NHEJ features in the human monocytic cell line, U937 ${ }^{99}$. They showed that aberrant double-strand break repair by NHEJ may lead to gross chromosomal rearrangements including interstitial deletion and large insertions.

In 40 gross deletions containing $5^{\prime}$ or $3^{\prime} \mathrm{LIR}$, positive moderate correlation between internal spacer length and deletion size $(r=$ $0.35, P<0.05)$ was found, similar to the group that included 138 LIRs. In addition, in 24 of 40 gross deletions, new LIRs between distant free ends containing LIR and no LIR were detected (Figures 4 and 5). These results show that LIRs with bigger loops cause larger deletions in human genome, suggesting that larger loops may give rise to greater stress and transition activity on the DNA strand during replication. Moreover, it was reported that bigger inverted repeats can dominate strand separation and B-Z transition, with Zhabinskaya and Benham, showing that long IRs occupy clinically important chromosomal breakpoints corresponded closely with translocation frequencies through probably cruciform extrusion ${ }^{100}$.

In conclusion, these results suggest that a LIR found in $5^{\prime}$ or $3^{\prime}$ breakpoints, may break DNA strand via cruciform structure and match with homolog sequences in other breakpoint site, resulting in a back-folded stem-loop structure during replication (Figure 6). In this way, DNA breakage may also occur in other breakpoint location containing no LIR. After double-strand breakages are formed at 5' and $3^{\prime}$ breakpoints, DNA ends between distant sites may combine by NHEJ, with following gene deletion.

As presented in Fig. 6, this model is supported with a study carried out in Saccharomyces cerevisiae ${ }^{101}$. In this study, IRs with internal spacer of $21 \mathrm{~kb}$ were placed into Saccharomyces cerevisiae chromosome. After double-strand break was induced, large dicentric inverted dimers were observed, leading to gross chromosomal rearrangements during anaphase stage. In addition, it has been suggested that p53-binding protein 1 (53BP1) combines free DNA ends between distant sites for $\mathrm{NHEJ}^{102}$.

An algorithm such as internal spacer $<2 \mathrm{~kb}$, stem copy identity $>85 \%$ and stem length $>30$ bp for recombinogenic LIRs in human and other organism genomes was suggested ${ }^{2}$. In the present study, only $35(25.36 \%)$ of 138 LIRs located close to the $5^{\prime}$ and $3^{\prime}$ breakpoints from 89 gross deletions, correspond to this criteria (see 


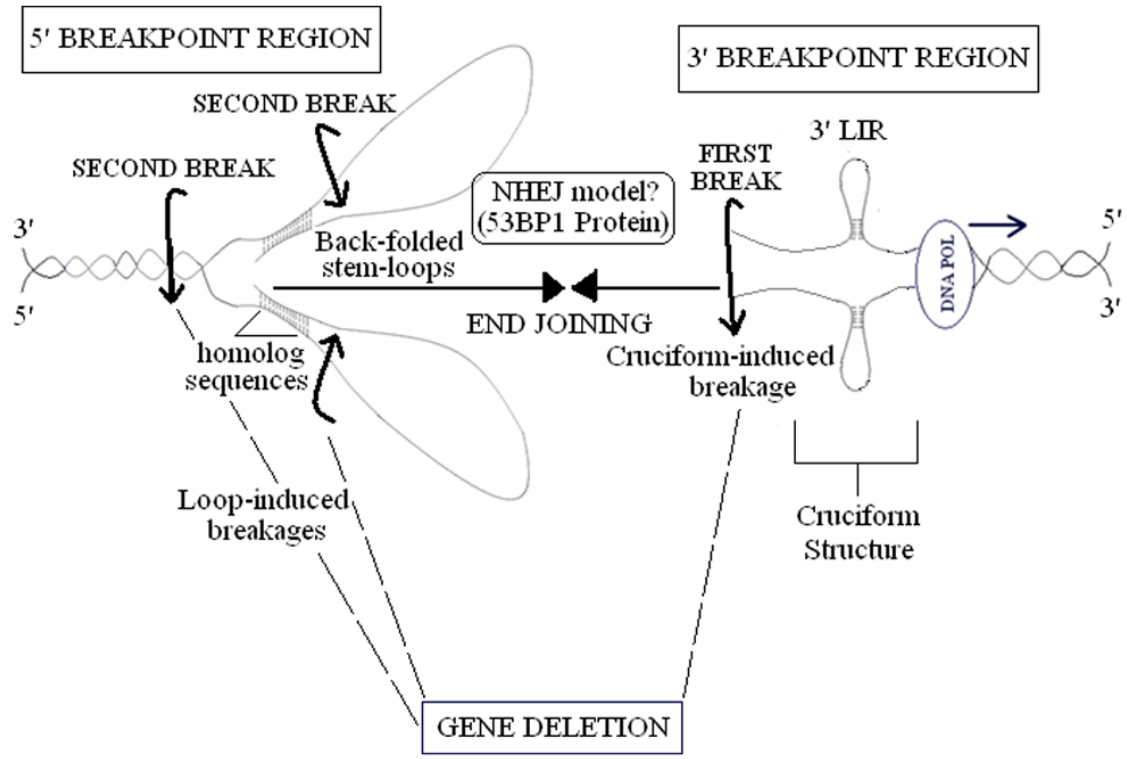

Figure 6 A model mechanism for single LIR-mediated gene deletion. LIR forming cruciform structure in the single strand DNA nearing 3' breakpoint of the gross gene deletion during replication is shown. After the first break is occurred in the vicinity of 3' LIR, second break is induced by back-folded stem-loop structures forming with homolog sequences between distant 5' and 3' breakpoint sites. Free DNA ends may combine via 53BP1-mediated NHEJ. Abbreviations: LIR, long inverted repeat; NHEJ, non-homologous end-joining.

Supplementary Table S3 online). However, the present findings indicate that significant relationship between LIR numbers and breakpoint regions of gross gene deletions. There is also a strongly positive correlation between $5^{\prime}$ and $3^{\prime}$ LIR numbers on breakpoint regions. On the other hand, $5^{\prime}$ and $3^{\prime}$ LIRs may have converse effects on deletion size. However, over-LIR intensity on $5^{\prime}$ or $3^{\prime}$ breakpoint locations cause smaller deletion sizes. In addition, this study showed that $3^{\prime}$ LIRs may be more active than $5^{\prime}$ LIRs in deletional and recombinational events. Moreover, internal spacer length affects breakage site and deletion size in the gross deletions. Therefore, the present study suggests necessity of a new algorithm for LIRs in breakpoint regions of gross gene deletions associated with human cancers and inherited genetic diseases.

Consequently, LIRs detected in genomic regions including breakpoint sequences of many gross gene deletions, may lead to cruciform structure formation during DNA replication and break DNA strand. After double-strand breaks occur in $5^{\prime}$ and $3^{\prime}$ breakpoints, gene deletions may be formed by combining free DNA ends with 53BP1 for NHEJ.

\section{Methods}

Gross gene deletions and breakpoint regions. In total, 109 gross gene deletions involving 63 genes, were obtained from the Human Gene Mutation Database (HGMD) $^{90,91}$ (see Supplementary Table S1 online). Base sequences of $5^{\prime}$ and $3^{\prime}$ deletion breakpoints were taken from references 33-89 listed in the $\mathrm{HGMD}^{90}$, or obtained from the Gross Rearrangement Breakpoint Database (GRaBD) ${ }^{22,93}$ (see Supplementary Table S1 online). Sequences of genes associated with deletions were downloaded from $\mathrm{NCBI}^{103}$. Gene accession numbers are provided (Table 1). Each deletion breakpoint sequence and corresponding genes were compared using NCBI BLAST $^{104}$, and breakpoint locations matched with related genes (Figure 1a). For each gene deletion, nucleotide positions of $5^{\prime}$ and $3^{\prime}$ breakpoints are shown (Table 1). Sequences $( \pm 10 \mathrm{~kb})$ spanning $5^{\prime}$ and $3^{\prime}$ breakpoints of gross gene deletions were

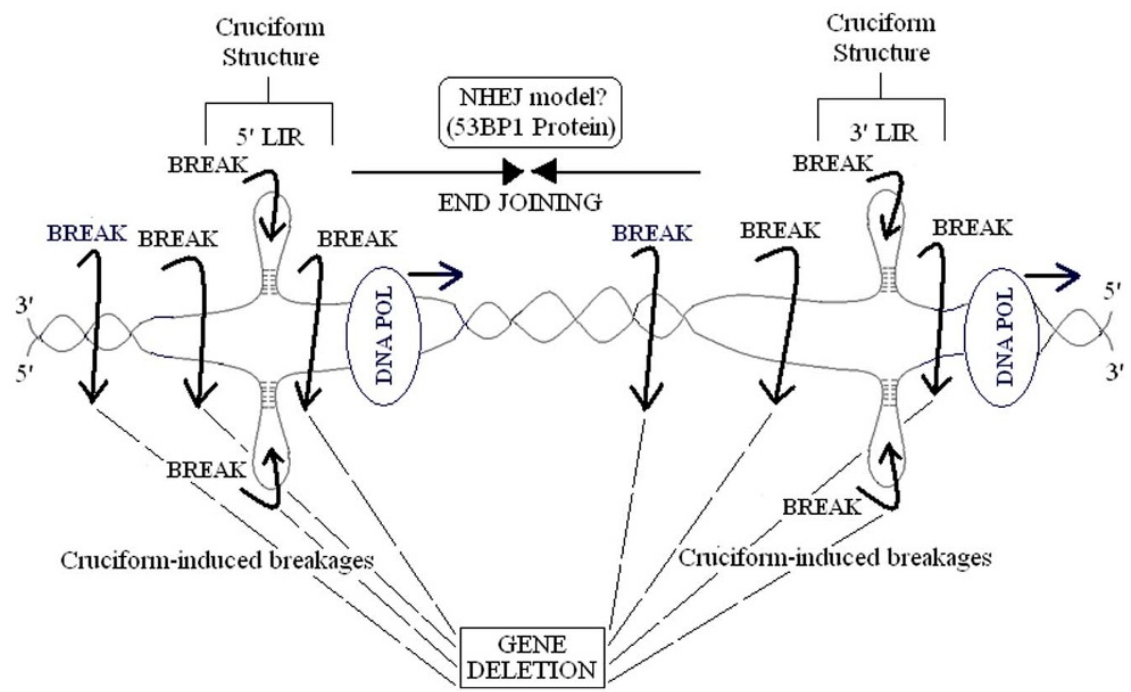

Figure $7 \mid$ A model mechanism for 5' and 3' LIRs-mediated gene deletion. Cruciform structures of LIRs are formed on DNA strands during replication, with breaks potentially occurring inside LIR or near locations. LIR-induced breakages at the $5^{\prime}$ and $3^{\prime}$ breakpoint sequences may cause gene deletion by enabling free DNA ends to recombine via 53BP1-mediated NHEJ. Abbreviations: LIR, long inverted repeat; NHEJ, non-homologous end-joining. 
included in the deletion group (see Supplementary Table S2 online). In total, 218 breakpoint sequences from 109 gross gene deletions were examined for LIR identification (Figure $1 \mathrm{~b}$ ).

For the control group, the DNA sequences of 68 different genes were downloaded from $\mathrm{NCBI}^{103}$ to be selected randomly (see Supplementary Table S2 online). Searching the $\mathrm{HGMD}^{90}$ site confirmed that selected control genes were not associated with deletions. Subsequently, $20 \mathrm{~kb}$ segments of DNA sequence from each control gene were included in the control group. In total, 220 control sequences were examined for LIR identification.

LIR identification. Identification of LIRs was performed within genomic regions (including the 218 breakpoint sequences from 109 gross gene deletions of 63 genes, and 220 control sequences from 68 genes) using IRF ${ }^{94,95}$ software (Figure 1b). The 2, 3, 5 and 40 (match, mismatch, indel and minimum score) parameters of IRF $^{94}$ were selected for identification.

LIRs with stem length $>20 \mathrm{bp}$, internal spacer of $0-10 \mathrm{~kb}$, stem identity $\geq 70 \%$, and within $\pm 10 \mathrm{~kb}$ fragments flanking each of the $5^{\prime}$ and $3^{\prime}$ breakpoint sequences of human gross gene deletions, or $20 \mathrm{~kb}$ segments of control genes, were investigated (Figure 1b). Total LIR numbers were determined (see Supplementary Table S2 online) and statistically compared between control and deletion groups. In addition, associations between LIR numbers on $5^{\prime}$ and $3^{\prime}$ breakpoints and also deletion size were statistically investigated.

Recently, Wang and Leung reported that LIRs with stem length $>30 \mathrm{bp}$, stem identity $>85 \%$ and internal spacer $<2 \mathrm{~kb}$ were highly recombinogenic in humans and other organisms ${ }^{2}$. It was also shown that long Alu IRs with $75 \%$ stem identity caused mild replication blockage in $E$. coli ${ }^{3}$. Thus, LIRs with distance of 0-3 kb from breakpoints, stem length $>20 \mathrm{bp}$, internal spacer of $0-2.5 \mathrm{~kb}$, and stem identity $\geq 70 \%$, were selected for determining associations between LIR features, distances from breakpoint and deletion size (see Supplementary Table S3 online; Figure 1c). At this stage, if many LIRs were observed in the same breakpoint region, the one which best fits the above criteria was chosen.

In addition, 40 of 109 gross gene deletions containing LIRs in only one of regions flanking $5^{\prime}$ and $3^{\prime}$ breakpoints, were further examined. The capacity to form new LIRs between breakpoints with LIRs and other breakpoint sites (including non LIRs of related deletion regions) was researched using IRF ${ }^{94}$.

For this, $5 \mathrm{~kb}$ of DNA sequence from breakpoints containing LIRs, and $10 \mathrm{~kb}$ of DNA sequence including other breakpoints but containing no LIRs, were combined before scanning for LIRs using IRF ${ }^{94}$. During this process, deleted gross genes were excluded and combined DNA sequences used. LIRs with stem length $>150$ bp and $>70 \%$ stem identity were selected for determining associations between LIR features and distance from breakpoints (see Supplementary Table S4 online).

Statistical analysis. Mann-Whitney $U$ test was used for statistical comparison of mean ranks of LIR numbers between gross gene deletion and control groups. Pearson's $(r)$ and Spearman's $\left(r_{s}\right)$ correlation coefficients were used to examine associations between LIR features (stem length and identity, and loop length), and distance from breakpoint and gene deletion size. In addition, Pearson's and Spearman's correlation coefficients were also used for determining associations between deletion size and $5^{\prime}$ and $3^{\prime}$ LIR numbers within $\pm 10 \mathrm{~kb}$ sequence spanning each breakpoint in 109 gross deletions. Correlation coefficients $\left(r, r_{s}\right)$ were classified according to criteria as low $(0.00-0.24)$, moderate $(0.25-0.49)$, strong $(0.50-0.74)$ and strongly $(0.75-1.00)^{105}$. Two-sided $P$ values $<0.05$ were considered statistically significant. All analyses were performed using SPSS 11.0 software (Chicago, USA)

1. Warburton, P. E., Giordano, J., Cheung, F., Gelfand, Y. \& Benson, G. Inverted repeat structure of the human genome: The $\mathrm{X}$-chromosome contains a preponderance of large, highly homologous inverted repeats that contain testes genes. Genome Res. 14, 1861-1869 (2004).

2. Wang, Y. \& Leung, F. C. C. Long inverted repeats in eukaryotic genomes: Recombinogenic motifs determine genomic plasticity. FEBS Lett. 580, 1277-1284 (2006).

3. Voineagu, I., Narayanan, V., Lobachev, K. S. \& Mirkin, S. M. Replication stalling at unstable inverted repeats: Interplay between DNA hairpins and fork stabilizing proteins. Proc. Natl. Acad. Sci. USA 105, 9936-9941 (2008).

4. Akgün, E. et al. Palindrome resolution and recombination in the mammalian germ line. Mol. Cell Biol. 17, 5559-5570 (1997).

5. Benham, C. J., Savitt, A. G. \& Bauer, W. R. Extrusion of an imperfect palindrome to a cruciform in superhelical DNA: Complete determination of energetics using a statistical mechanical model. J. Mol. Biol. 316, 563-581 (2002).

6. Gordenin, D. A. et al. Inverted DNA repeats: a source of eukaryotic genomic instability. Mol. Cell Biol. 13, 5315-5322 (1993).

7. Nag, D. K. \& Kurst, A. A 140-bp-long palindromic sequence induces doublestrand breaks during meiosis in the yeast Saccharomyces cerevisiae. Genetics 146, 835-847 (1997).

8. Upadhyaya, M. et al. Gross deletions of the neurofibromatosis type 1 (NF1) gene are predominantly of maternal origin and commonly associated with a learning disability, dysmorphic features and developmental delay. Hum. Genet. 102, 591-597 (1998).

9. Albrecht, P. et al. Spectrum of gross deletions and insertions in the RB1 gene in patients with retinoblastoma and association with phenotypic expression. Hum. Mutat. 26, 437-445 (2005).
10. Férec, C. et al. Gross genomic rearrangements involving deletions in the CFTR gene: characterization of six new events from a large cohort of hitherto unidentified cystic fibrosis chromosomes and meta-analysis of the underlying mechanisms. Eur. J. Hum. Genet. 14, 567-576 (2006).

11. Preisler-Adams, S. et al. Gross rearrangements in BRCA1 but not BRCA2 play a notable role in predisposition to breast and ovarian cancer in high-risk families of German origin. Cancer Genet. Cytogenet. 168, 44-49 (2006).

12. Ashton, E. J., Yau, S. C., Deans, Z. C. \& Abbs, S. J. Simultaneous mutation scanning for gross deletions, duplications and point mutations in the DMD gene. Eur. J. Hum. Genet. 16, 53-61 (2008).

13. Owens, M., Ellard, S. \& Vaidya, B. Analysis of gross deletions in the MEN1 gene in patients with multiple endocrine neoplasia type 1. Clin. Endocrinol. (Oxf) 68, 350-354 (2008)

14. Lupski, J. R. \& Stankiewicz, P. Genomic disorders: Molecular mechanisms for rearrangements and conveyed phenotypes. PLoS Genet. 1, e49; DOI: 10.1371/ pgen0010049 (2005).

15. Gu, W., Zhang, F. \& Lupski, J. R. Mechanisms for human genomic rearrangements. Pathogenetics 1, 4 (2008).

16. Shaw, C. J. \& Lupski, J. R. Implications of human genome architecture for rearrangement-based disorders: the genomic basis of disease. Hum. Mol. Genet. 13, R57-R64 (2004).

17. Bacolla, A. et al. Breakpoints of gross deletions coincide with non-B DNA conformations. Proc. Natl. Acad. Sci. USA 101, 14162-14167 (2004).

18. Bacolla, A. \& Wells, R. D. Non-B DNA conformations as determinants of mutagenesis and human disease. Mol. Carcinog. 48, 273-285 (2009).

19. Krawczak, M. \& Cooper, D. N. Gene deletions causing human genetic disease: mechanisms of mutagenesis and the role of the local DNA sequence environment. Hum. Genet. 86, 425-441 (1991).

20. Canning, S. \& Dryja, T. P. Short, direct repeats at the breakpoints of deletions of the retinoblastoma gene. Proc. Natl. Acad. Sci. USA 86, 5044-5048 (1989).

21. McNaughton, J. C. et al. Is gene deletion in eukaryotes sequence-dependent? A study of nine deletion junctions and nineteen other deletion breakpoints in intron 7 of the human dystrophin gene. Gene 222, 41-51 (1998).

22. Chuzhanova, N., Abeysinghe, S. S., Krawczak, M. \& Cooper, D. N. Translocation and gross deletion breakpoints in human inherited disease and cancer II: Potential involvement of repetitive sequence elements in secondary structure formation between DNA ends. Hum. Mutat. 22, 245-251 (2003).

23. Xie, F. et al. A novel Alu-mediated $61-\mathrm{kb}$ deletion of the von Willebrand factor $(V W F)$ gene whose breakpoints co-locate with putative matrix attachment regions. Blood Cells Mol. Dis. 36, 385-391 (2006).

24. Vissers, L. E. L. M. et al. Rare pathogenic microdeletions and tandem duplications are microhomology-mediated and stimulated by local genomic architecture. Hum. Mol. Genet. 18, 3579-3593 (2009).

25. Zhang, F., Carvalho, C. M. B. \& Lupski, J. R. Complex human chromosomal and genomic rearrangements. Trends Genet. 25, 298-307 (2009).

26. Lobachev, K. S. et al. Factors affecting inverted repeat stimulation of recombination and deletion in Saccharomyces cerevisiae. Genetics 148, 1507-1524 (1998).

27. Eichman, B. F., Vargason, J. M., Mooers, B. H. M. \& Ho, P. S. The Holliday junction in an inverted repeat DNA sequence: Sequence effects on the structure of four-way junctions. Proc. Natl. Acad. Sci. USA 97, 3971-3976 (2000).

28. Houck, C. M., Rinehart, F. P. \& Schmid, C. W. A ubiquitous family of repeated DNA sequences in the human genome. J. Mol. Biol. 132, 289-306 (1979).

29. Biezunski, N. Structure and distribution of inverted repeats (palindromes). I. Analysis of DNA of Drosophila melanogaster. Chromosoma 84, 87-109 (1981a).

30. Biezunski, N. Structure and distribution of inverted repeats (palindromes). II. Analysis of DNA of the mouse. Chromosoma 84, 111-129 (1981b).

31. Russell, G. C. \& Mann, N. H. Analysis of inverted repeat DNA in the genome of Rhodomicrobium vannielii. J. Gen. Microbiol. 132, 325-330 (1986).

32. Collick, A. et al. Instability of long inverted repeats within mouse transgenes. EMBO J. 15, 1163-1171 (1996)

33. Montagna, M. et al. Genomic rearrangements account for more than one-third of the BRCA1 mutations in northern Italian breast/ovarian cancer families. Hum. Mol. Genet. 12, 1055-1061 (2003)

34. Tancredi, M. et al. Haplotype analysis of BRCA1 gene reveals a new gene rearrangement: characterization of a $19.9 \mathrm{kbp}$ deletion. Eur. J. Hum. Genet. 12, 775-777 (2004)

35. Agata, S. et al. Prevalence of BRCA1 genomic rearrangements in a large cohort of Italian breast and breast/ovarian cancer families without detectable BRCA1 and BRCA2 point mutations. Genes Chromosomes Cancer 45, 791-797 (2006).

36. Agata, S. et al. Large genomic deletions inactivate the BRCA2 gene in breast cancer families. J. Med. Genet. 42, e64; DOI:10.1136/jmg032789 (2005).

37. Tournier, I. et al. Significant contribution of germline BRCA2 rearrangements in male breast cancer families. Cancer Res. 64, 8143-8147 (2004).

38. Vandenbroucke, I. et al. Genetic and clinical mosaicism in a patient with neurofibromatosis type 1. Hum. Genet. 114, 284-290 (2004).

39. Takahashi, M. et al. Detection of APC gene deletion by double competitive polymerase chain reaction in patients with familial adenomatous polyposis. Int. J. Oncol. 29, 413-421 (2006).

40. Longa, L. et al. TSC1 and TSC2 deletions differ in size, preference for recombinatorial sequences, and location within the gene. Hum. Genet. 108 156-166 (2001) 
41. Tadokoro, K. et al. Intragenic homozygous deletion of the WT1 gene in Wilms' tumor. Oncogene 7, 1215-1221 (1992).

42. Gualandi, F. et al. Multiple exon skipping and RNA circularisation contribute to the severe phenotypic expression of exon 5 dystrophin deletion. J. Med. Genet. 40, e100 (2003).

43. Chibon, F. et al. Contribution of PTEN large rearrangements in Cowden disease: a multiplex amplifiable probe hybridisation (MAPH) screening approach. J. Med. Genet. 45, 657-665 (2008).

44. Kikuchi, M., Ohkura, N., Yamaguchi, K., Obara, T. \& Tsukada, T. Gene dose mapping delineated boundaries of a large germline deletion responsible for multiple endocrine neoplasia type 1. Cancer Lett. 208, 81-88 (2004).

45. Jo, E. K. et al. Identification of mutations in the Bruton's tyrosine kinase gene, including a novel genomic rearrangements resulting in large deletion, in Korean X-linked agammaglobulinemia patients. J. Hum. Genet. 48, 322-326 (2003).

46. Palena, A., Blau, A., Stamatoyannopoulos, G. \& Anagnou, N. P. Eastern European (delta beta) zero-thalassemia: molecular characterization of a novel 9,1-kb deletion resulting in high levels of fetal hemoglobin in the adult. Blood 83, 3738-3745 (1994).

47. Mitui, M. et al. Independent mutational events are rare in the ATM gene: haplotype prescreening enhances mutation detection rate. Hum. Mutat. 22, 43-50 (2003).

48. Li, L. et al. Distinct patterns of germ-line deletions in $M L H 1$ and $M S H 2$ : the implication of Alu repetitive element in the genetic etiology of Lynch syndrome (HNPCC). Hum. Mutat. 27, 388 (2006)

49. van der Klift, H. et al. Molecular characterization of the spectrum of genomic deletions in the mismatch repair genes MSH2, MLH1, MSH6, and PMS2 responsible for hereditary nonpolyposis colorectal cancer (HNPCC). Genes Chromosomes Cancer 44, 123-138 (2005).

50. Myerowitz, R. \& Hogikyan, N. D. A deletion involving Alu sequences in the betahexosaminidase alpha-chain gene of French Canadians with Tay-Sachs disease. J. Biol. Chem. 262, 15396-15399 (1987).

51. Lauderdale, J. D., Wilensky, J. S., Oliver, E. R., Walton, D. S. \& Glaser, T. 3' deletions cause aniridia by preventing PAX6 gene expression. Proc. Natl. Acad. Sci. USA 97, 13755-13759 (2000).

52. van Zelm, M. C. et al. Gross deletions involving IGHM, BTK, or Artemis: a model for genomic lesions mediated by transposable elements. Am. J. Hum. Genet. 82, 320-332 (2008).

53. Baronciani, L. \& Beutler, E. Molecular study of pyruvate kinase deficient patients with hereditary nonspherocytic hemolytic anemia. J. Clin. Invest. 95, 1702-1709 (1995)

54. Gromoll, J., Eiholzer, U., Nieschlag, E. \& Simoni, M. Male hypogonadism caused by homozygous deletion of exon 10 of the luteinizing hormone $(L H)$ receptor: differential action of human chorionic gonadotropin and LH. J. Clin. Endocrinol. Metab. 85, 2281-2286 (2000).

55. Shibata, M. et al. An alloantibody recognizing the FVIII A1 domain in a patient with CRM reduced haemophilia A due to deletion of a large portion of the A1 domain DNA sequence. Thromb. Haemost. 84, 442-448 (2000).

56. Imai, K. et al. Clinical course of patients with WASP gene mutations. Blood 103, 456-464 (2004).

57. Peake, I. R. et al. Severe type III von Willebrand's disease caused by deletion of exon 42 of the von Willebrand factor gene: family studies that identify carriers of the condition and a compound heterozygous individual. Blood 75, 654-661 (1990).

58. Seifert, W. et al. Mutational spectrum of $\mathrm{COH} 1$ and clinical heterogeneity in Cohen syndrome. J. Med. Genet. 43, e22; DOI: 10.1136/jmg039867 (2006)

59. Wirth, B. et al. Quantitative analysis of survival motor neuron copies: Identification of subtle SMN1 mutations in patients with spinal muscular atrophy, genotype-phenotype correlation, and implications for genetic counseling. Am. J. Hum. Genet. 64, 1340-1356 (1999).

60. Jaeken, J. et al. Deletion of PREPL, a gene encoding a putative serine oligopeptidase, in patients with hypotonia-cystinuria syndrome. Am. J. Hum. Genet. 78, 38-51 (2006).

61. Roche, O. et al. Hereditary angioedema: the mutation spectrum of SERPING1/ C1NH in a large Spanish cohort. Hum. Mutat. 26, 135-144 (2005).

62. Baysal, B. E. et al. An Alu-mediated partial SDHC deletion causes familial and sporadic paraganglioma. J. Med. Genet. 41, 703-709 (2004).

63. Borozdin, W. et al. SALL4 deletions are a common cause of Okihiro and acrorenal-ocular syndromes and confirm haploinsufficiency as the pathogenic mechanism. J. Med. Genet. 41, e113; DOI:10.1136/jmg019901 (2004).

64. Schmidel, D. K. et al. A 5,3-kb deletion including exon XIII of the protein $\mathrm{S} \alpha$ gene occurs in two protein S-deficient families. Blood 77, 551-559 (1991).

65. Bergmann, C. et al. Multi-exon deletions of the PKHD1 gene cause autosomal recessive polycystic kidney disease (ARPKD). J. Med. Genet. 42, e63; DOI: 10.1136/jmg032318 (2005).

66. Thomas, R. et al. Identification of mutations in the repeated part of the autosomal dominant polycystic kidney disease type 1 gene, $P K D 1$, by long-range PCR. Am. J. Hum. Genet. 65, 39-49 (1999).

67. Li, Y. et al. Clinicogenetic study of PINK1 mutations in autosomal recessive earlyonset parkinsonism. Neurology 64, 1955-1957 (2005).

68. Clarimon, J. et al. Defining the ends of Parkin exon 4 deletions in two different families with Parkinson's disease. Am. J. Med. Genet. B. Neuropsychiatr Genet. 133B, 120-123 (2005).
69. Yi, Z. et al. A 122,5-kilobase deletion of the $P$ gene underlies the high prevalence of oculocutaneous albinism type 2 in the Navajo population. Am. J. Hum. Genet. 72, 62-72 (2003)

70. Douglas, J. et al. Partial NSD1 deletions cause $5 \%$ of Sotos syndrome and are readily identifiable by multiplex ligation dependent probe amplification. J. Med. Genet. 42, e56; DOI: 10.1136/jmg031930 (2005).

71. Leegwater, P. A. et al. Identification of novel mutations in $M L C 1$ responsible for megalencephalic leukoencephalopathy with subcortical cysts. Hum. Genet. 110, 279-283 (2002).

72. Poulsen, L. et al. X-linked recessive Menkes disease: identification of partial gene deletions in affected males. Clin. Genet. 62, 449-457 (2002).

73. Schöneberg, T. et al. Compound deletion of the rhoGAP C1 and V2 vasopressin receptor genes in a patient with nephrogenic diabetes insipidus. Hum. Mutat. 14, 163-174 (1999).

74. Audrézet, M. P. et al. Genomic rearrangements in the CFTR gene: extensive allelic heterogeneity and diverse mutational mechanisms. Hum. Mutat. 23, 343-357 (2004).

75. Dörk, T. et al. Characterization of a novel 21-kb deletion, CFTRdele2,3(21 kb), in the CFTR gene: a cystic fibrosis mutation of Slavic origin common in Central and East Europe. Hum. Genet. 106, 259-268 (2000).

76. Abicht, A. et al. A newly identified chromosomal microdeletion and an N-box mutation of the AChR epsilon gene cause a congenital myasthenic syndrome. Brain 125, 1005-1013 (2002).

77. Huber, M. et al. Deletion of the cytoplasmatic domain of BP180/collagen XVII causes a phenotype with predominant features of epidermolysis bullosa simplex. $J$. Invest. Dermatol. 118, 185-192 (2002).

78. Morgan, N. V., Tipping, A. J., Joenje, H. \& Mathew, C. G. High frequency of large intragenic deletions in the Fanconi anemia group A gene. Am. J. Hum. Genet. 65, 1330-1341 (1999).

79. Tipping, A. J. et al. Molecular and genealogical evidence for a founder effect in Fanconi anemia families of the Afrikaner population of South Africa. Proc. Natl. Acad. Sci. USA 98, 5734-5739 (2001).

80. Liu, W., Schrijver, I., Brenn, T., Furthmayr, H. \& Francke, U. Multi-exon deletions of the FBN1 gene in Marfan syndrome. BMC Med. Genet. 2, 11 (2001).

81. Has, C. et al. Molecular basis of Kindler syndrome in Italy: novel and recurrent Alu/Alu recombination, splice site, nonsense, and frameshift mutations in the KIND1 gene. J. Invest. Dermatol. 126, 1776-1783 (2006).

82. Spena, S. et al. Congenital afibrinogenaemia caused by uniparental isodisomy of chromosome 4 containing a novel $15-\mathrm{kb}$ deletion involving fibrinogen $\mathrm{A} \alpha$-chain gene. Eur. J. Hum. Genet. 12, 891-898 (2004)

83. Beysen, D. et al. Deletions involving long-range conserved nongenic sequences upstream and downstream of FOXL2 as a novel disease-causing mechanism in blepharophimosis syndrome. Am. J. Hum. Genet. 77, 205-218 (2005).

84. Huie, M. L., Anyane-Yeboa, K., Guzman, E. \& Hirschhorn, R. Homozygosity for multiple contiguous single-nucleotide polymorphisms as an indicator of large heterozygous deletions: identification of a novel heterozygous 8-kb intragenic deletion (IVS7-19 to IVS15-17) in a patient with glycogen storage disease type II. Am. J. Hum. Genet. 70, 1054-1057 (2002).

85. Tay, S. K. et al. Fatal infantile neuromuscular presentation of glycogen storage disease type IV. Neuromuscul. Disord. 14, 253-260 (2004)

86. Besson, A. et al. Primary GH insensitivity '(Laron syndrome) caused by a novel $4 \mathrm{~kb}$ deletion encompassing exon 5 of the $\mathrm{GH}$ receptor gene: effect of intermitten long-term treatment with recombinant human IGF-I. Eur. J. Endocrinol. 150, 635-642 (2004)

87. Kornreich, R., Bishop, D. F. \& Desnick, R. J. $\alpha$-galactosidase A gene rearrangements causing Fabry disease. Identification of short direct repeats at breakpoints in an Alu-rich gene. J. Biol. Chem. 265, 9319-9326 (1990).

88. Johnston, J. J. et al. Clinical and molecular delineation of the Greig cephalopolysyndactyly contiguous gene deletion syndrome and its distinction from acrocallosal syndrome. Am. J. Med. Genet. 123A, 236-242 (2003).

89. Jia, S. Q. et al. $\alpha^{0}$ thalassaemia as a result of a novel $11,1 \mathrm{~kb}$ deletion eliminating both of the duplicated $\alpha$ globin genes. J. Clin. Pathol. 57, 164-167 (2004).

90. Human Gene Mutation Database (HGMD) (2007). Available at: http://www. hgmd.cf.ac.uk/ac/index.php (Accessed: 3rd January 2009).

91. Stenson, P. D. et al. The human gene mutation database: 2008 update. Genome Med. 1, 13 (2009)

92. Gross Rearrangement Breakpoint Database (GRaBD) (2004). Available at: http:// www.uwcm.ac.uk/uwcm/mg/grabd/. (Accessed: 25th December 2008).

93. Abeysinghe, S. S., Chuzhanova, N., Krawczak, M., Ball, E. V. \& Cooper, D. N. Translocation and gross deletion breakpoints in human inherited disease and cancer I. Nucleotide composition and recombination-associated motifs. Hum. Mutat. 21, 229-244 (2003).

94. Inverted Repeat Finder (IRF) (2006). Available at: https://tandem.bu.edu/cgi-bin/ $\mathrm{irdb} /$ irdb.exe. (Accessed: 9th January 2009).

95. Benson, G. Tandem repeats finder: A program to analyze DNA sequences. Nucleic Acids Res. 27, 573-580 (1999).

96. Saini, N. et al. Fragile DNA motifs trigger mutagenesis at distant chromosoma loci in Saccharomyces cerevisiae. PLOS Genet. 9, e1003551; DOI: 10.1371/ pgen1003551 (2013).

97. Lim, C. et al. Size of gene specific inverted repeat-dependent gene deletion in Saccharomyces cerevisiae. PLoS One 8, e72137; DOI: 10.1371/pone0072137 (2013). 
98. Weiss, U. \& Wilson, J. H. Repair of single-stranded loops in heteroduplex DNA transfected into mammalian cells. Proc. Natl. Acad. Sci. USA 84, 1619-1623 (1987).

99. Varga, T. \& Aplan, P. D. Chromosomal aberrations induced by double strand DNA breaks. DNA Repair 4, 1038-1046 (2005).

100. Zhabinskaya, D. \& Benham, C. J. Competitive superhelical transitions involving cruciform extrusion. Nucleic Acids Res. 41, 9610-9621 (2013).

101. VanHulle, K. et al. Inverted DNA repeats channel repair of distant double-strand breaks into chromatid fusions and chromosomal rearrangements. Mol. Cell Biol. 27, 2601-2614 (2007)

102. van Gent, D. C. Reaching out for the other end with p53-binding protein 1. Trends Biochem. Sci. 34, 226-229 (2009).

103. National Center for Biotechnology Information (NCBI) (1988). Available at: http://www.ncbi.nlm.nih.gov. (Accessed: 20th December 2008).

104. NCBI BLAST (1990). Available at: http://www.ncbi.nlm.nih.gov/blast. (Accessed: 4th January 2009).

105. Aksakoglu, G. [Korelasyon ve Regresyon (Correlation and Regression)] Sağlıkta araştırma teknikleri ve analiz yöntemleri (Research techniques and analysis methods in health) [Aksakoglu, G. (1st ed.)] [306-320] (Dokuz Eylul University, Izmir, 2001).

\section{Acknowledgments}

I thank Ozden Ulker for his critical review. In addition, I thank to EDANZGROUPG (www. edanzediting.com) for copy editing of the manuscript.

\section{Author contributions}

N.A. conceived the study and performed the bioinformatics methods and analysed the statistical data using SPSS 11.0 software, wrote the manuscript and revised it, and prepared all figures and tables.

\section{Additional information}

Supplementary information accompanies this paper at http://www.nature.com/ scientificreports

Competing financial interests: The authors declare no competing financial interests.

How to cite this article: Aygun, N. Correlations between long inverted repeat (LIR) features, deletion size and distance from breakpoint in human gross gene deletions. Sci. Rep. 5, 8300; DOI:10.1038/srep08300 (2015).

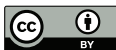

This work is licensed under a Creative Commons Attribution 4.0 International License. The images or other third party material in this article are included in the article's Creative Commons license, unless indicated otherwise in the credit line; if the material is not included under the Creative Commons license, users will need to obtain permission from the license holder in order to reproduce the material. To view a copy of this license, visit http://creativecommons.org/licenses/by/4.0/ 